\title{
MATIZ-ACIÓN DE LA ADOLESCENCIA BAJO LOS COLORES DE LA PRIVACIÓN DE LA LIBERTAD POR EL SRPA
}

\author{
Claudia E Gómez Peláez \\ Universidad del Cauca, Colombia
}

http://dx.doi.org/10.5209/NOMA.54181

\begin{abstract}
Resumen.- Cuando llega el hito de la adolescencia, lo transversaliza una sanción impuesta por el Sistema de Responsabilidad Penal para Adolescentes SRPA, cuando se vislumbra la posibilidad de ser: grande, autónomo, participativo y libre, se encuentran, privados de la libertad como única posibilidad de restituir los derechos a quien se sabe victimario por el crimen cometido y víctima de la sociedad impuesta; quienes pueden ser nobles, sabios, bárbaros, víctimas o agresores, quienes pueden ser salvajes Trovillot (2011), que necesitan disciplinamiento, para resocializarse e incorporarse nuevamente a la sociedad, como cuerpos dóciles Foucault (2005). Así se esboza, tan sólo una de las tantas pinceladas de un cuadro con bastantes relieves y diferentes texturas, de lo que fue la investigación etnográfica. Sobre la cual, necesitaría varias capas, para lograr pintar la realidad que atravesaban sólo 108 adolescentes, privados de la libertad en el Departamento del Cauca, sin contar con los relatos del $96.4 \%$ que aproximadamente suman el resto de adolescentes privados de la libertad en Colombia.
\end{abstract}

Palabras clave: Adolescentes, Sistema de Responsabilidad Penal para adolescentes, Justicia Restaurativa.

\begin{abstract}
When the milestone of adolescence arrives, it cuts across a sanction imposed by the Criminal Responsibility System for Adolescents PARR, when the possibility of being in sight: large, autonomous, participative and free, are deprived of freedom as the only possibility of restore the rights offender who is known for the crime and victim of society imposed; who may be noble, wise, barbarians, victims or attackers, who can be wild Trouillot (2011), they need discipline, to resocialized and join society again as docile bodies Foucault (2005). Thus it outlined, only one of the many touches of a picture with many reliefs and textures, what was the ethnographic research. On which it would need several layers to achieve paint reality spanning only 108 adolescents deprived of liberty in the department of Cauca, without the accounts of $96.4 \%$ to approximately account for other adolescents deprived of freedom in Colombia .
\end{abstract}

Keywords: Adolescents Criminal Responsibility System for Adolescents, Restorative Justice.

\section{Presentación}

Los adultos un poco orgullosos de su transcurrir por la vida y de la sabiduría adquirida en ese transcurrir, dejamos de lado la necesidad de contextualizarnos en los aconteceres de este mundo cambiante y acelerado, razón por la cual los adolescentes tienen un conocimiento diferente, no menos importante que el nuestro. Ese conocimiento de la calle, las parrandas, las pandillas, las drogas el sexo desaforado y un sinnúmero de vivencias que a temprana edad terminan incorporándose a su ser, a su pensamiento y por tanto a su actuar. 
Entrar a ese mundo complejo del adolescente no es fácil, primero por la diferencia de vivencias y luego por lo reservados que se tornan, colocando verdaderas barreras para resguardar su identidad; lo cual desde una postura del "tener", es representada por "símbolos, lenguaje, hábitos, costumbres, grupos de referencia, sexualidad, valores, normas, roles, memoria histórica, trabajo". (Max Neef, 1998, p 59), protegiendo lo que hace parte de sus códigos secretos y códigos de lealtad.

Con más motivo, la investigación etnográfica llevada a cabo durante 2 años, me permitió comprender que los artífices de este escrito, no son personas diferentes a usted y a mí; diferentes a los seres cercanos a nosotros. Aquellos, a quienes la sociedad rotula como delincuentes, no son personas menos dignos que usted o que yo, pero entre los cuales sí hay una gran diferencia con relación a usted o a mí y es que ellos, los adolescentes más "jodidos" no han tenido las mismas oportunidades que usted y que yo. Los cuales crecieron en un entorno no favorable y por circunstancias sociales, su vida se ha enmarcado en situaciones de violencia, discriminación y violación de sus derechos.

Lo que se van a encontrar en el transcurso del presente documento, será la descripción de un estudio de caso, realizado con un operador del Sistema de Responsabilidad Penal para Adolescentes de Colombia, que intenta matizar la vida de los adolescentes que acoge como privados de la libertad, intentando además incidir sobre sus proyectos de vida (Zuazua, 2007), durante el tiempo que le haya impuesto el juez. Sin embargo, un caso resulta insuficiente, para poder representar una realidad fuera de control de entes sociales, como el Estado, la iglesia y la familia. En ese sentido, se presentará la cotidianidad y lógica subjetiva, restitución de derechos y significados del contexto investigativo. El cual se toma como una escena de las tantas vividas durante la investigación realizada.

\section{Contexto}

En este apartado, se contextualizará sobre la cotidianidad de los adolescentes que se encuentran privados de la libertad, por el Sistema de Responsabilidad Penal para Adolescentes-Colombiano, como consecuencia de actos delictivos. Específicamente, la cotidianidad de los adolescentes, cuyo acto punitivo lo han llevado a cabo en el departamento del Cauca y por tanto la sanción deben cumplirla en el mismo departamento. Acto seguido, se describirá el proceso de restitución de derechos que se da en el adolescente entre 14 y 18 años en el contexto de internamiento.

Las expectativas que se puedan tener frente a este relato, pueden ser diversas; por lo que preciso decir que constituye sólo una escena de todas las que podrían resultar de mi trabajo de campo; adicionalmente expongo, mi gran esfuerzo para salir de la comodidad de mi disciplina 
como psicóloga, evitando realizar interpretaciones bajo sus postulados, en cambio sí adentrarme en el proceso de comprensión de la práctica de los actores de este escenario social tan amplio y complejo, para darle objetividad de cara a develar verbalizaciones, motivaciones y percepciones de una situación, en la cual se encuentran inmersos de manera fortuita y ajena a su voluntad. De modo que me acuño en la mirada que hace (Runciman, 1983) citado por Guber frente al elemento distintivo de las ciencias sociales "la descripción", aludiendo que:

En todas las ciencias comparten dos niveles de comprensión: el primario o reporte informa qué ha ocurrido (el "qué"); el secundario o explicación alude a sus causas (el "por qué"); pero las ciencias sociales no puede prescindir de un nivel terciario de comprensión que es la descripción, el cual se ocupa de lo que ocurrió según sus agentes (el "cómo es" para ellos). Un investigador social no puede entender una acción sin comprender los términos en que la caracterizan sus protagonistas. (Guber, 2001, p.32).

Desde esta perspectiva daré un vistazo a manera de caracterización del contexto y sus actores. En consecuencia, prima exponer quiénes son los actores principales que llamaron la atención de mi investigación y que me permitieron captar sus imaginarios frente a un actuar dibujado por quienes imponen la norma, pero que cobra legitimización a partir de las verdaderas prácticas que acompañan el cotidiano vivir, de los mismos, mientras dura su tiempo de internamiento. En ese sentido quiero exponer que están los actores que desarrollan o aplican el Sistema de Responsabilidad Penal (en lo consecutivo SRP) como figuras restaurativas más que punitivas y de otro lado los actores que se someten al SRP conscientes de que es su castigo justo o injusto, no puede suplir las necesidades a las que han estado expuestos durante toda su vida, como tampoco les puede hacer olvidar de dónde vienen y a dónde tienen que volver.

Estos protagonistas, adolescentes, son infractores. Acusados por haber infringido la ley, es decir los adolescentes mayores de 14 años y menores de 18 años que fueron encontrados responsables de la comisión de delitos de homicidio doloso, secuestro o extorsión en todas sus modalidades; los cuales difieren del proceso a seguir con los menores de catorce años ya que los menores de 14 años no pueden ser juzgados ni declarados responsables penalmente, ni sometidos a sanciones penales privados de la libertad. Ésta, se da, en un medio denominado internamiento preventivo donde probablemente algunos o varios de los adolescentes cumplen su mayoría de edad y cuya sanción no cambia por dicha condición, garante de los derechos del menor. Atendidos bajo la dinámica particular que plantee el programa en el cual esté internado e independiente de que en ese mismo programa hayan adolescentes que transiten por edades inferiores o mayores a la suya.No 
menos importante, resulta el escenario social, donde se dio la interacción con estos protagonistas. Siendo el Instituto de Formación Toribio Maya ${ }^{1}$. Creado inicialmente como una dependencia adscrita a la Gobernación del Cauca. Toda su planta de personal y locaciones eran administradas por dicha Gobernación.2; denominada inicialmente, Casa del Menor, empezó a funcionar en el edificio donde hoy es secretaria municipal de obras públicas. Su función era ofrecer el servicio de internado a niños, niñas y adolescentes que estuvieran en condiciones de calle, por consiguiente el Instituto era proveedor de satisfactores a necesidades que según (Max-Neef, 2004), pudieran clasificarse desde una arista de desarrollo a escala humana como la subsistencia, la protección básicamente, porque las otras no alcanzaban a ser transversalizadas por la atención que ofrecían. A continuación, se muestran algunas imágenes de las locaciones actuales, que para el año de 1971 fueron empleadas para alojar la población mencionada en el presente.

Posteriormente en el año 1998, el entonces Gobernador César Vergara Mendoza, consideraba que quien debería darle administración a dicha labor social, era una institución de amplia trayectoria en el trabajo con poblaciones niños, niñas y adolescentes en condiciones de vulnerabilidad, que como consecuencia habían tomado conductas de calle; en tanto el internamiento constituye la medicina que le aplicamos a un mal social ${ }^{3}$. Así, se dio a la tarea de buscar que dicha organización fuera religiosa para garantizar la optimización de los recursos y de prácticas soportadas en derechos humanos.

De tal suerte, se gestionó con la Congregación de Religiosos Terciarios Capuchinos, la administración de los recursos destinados a la protección y subsistencia de la población en mención. Esta Congregación, tiene una trayectoria internacional en trabajo con menores infractores de la ley, quienes hoy operan El Sistema de Responsabilidad Penal en Colombia, de manera prioritaria frente a otros operadores.

A continuación, se celebró el contrato de prestación de servicios entre la Gobernación del Departamento y La Congregación, mediante decreto departamental nro. 687 del 7 de septiembre de 1988, de acuerdo a la autorización de la Junta directiva del IFTM, creada mediante decreto nro. 806 de 1973. El actual decreto, derogaba cualquier disposición anterior, a la vez que le quitaba las facultades que tuvo la junta directiva, a modo de poder asignarle todas las

\footnotetext{
1 Creado mediante ordenanza 15 de diciembre 28 de 1971, de la Asamblea del Cauca.

2 Entrevista realizada a (Doña Estella Londoño de Vélez, 2012), coordinadora académica del IFTM y persona que ha estado en dicho instituto desde su creación.

3 Entrevista realizada al Diputado (Néstor Paz, 2012). Contralor Departamental del Cauca para el año 1988.
} 
responsabilidades al nuevo contratista. El funcionamiento de los servicios, habían sido trasladados al Barrio Villa del Norte a razón del terremoto de 1983.

En estas instalaciones, inició la labor Amigoniana la Congregación mencionada anteriormente, bajo la administración de Fray Domingo Vergara, quien posteriormente fue trasladado a otras sedes y quien se encuentra nuevamente al frente de la administración desde hace 6 años. De modo que, en el año de 1988, la administración Municipal, quien hasta ese momento había sido la encargada de administrar la llamada "Casa de Menores", luego "Casa de Menores Toribio Maya" en honor al médico que llevó su nombre en alto y su misión a los más necesitados, durante su existencia y posteriormente en el año 1971 llamado "Instituto de Formación Toribio Maya" ubicado en obras públicas, había trasladado sus servicios a este terreno, donde se dio a la tarea de construir el edifico para tal fin ${ }^{4}$, hoy cuenta con piscina, canchas de fútbol, baloncesto, salones para recibir clases, talleres para la formación técnica en diversas áreas y abundante zona verde. No sólo ha debido mejorar su infraestructura física, sino también que ha debido asumir diferentes retos como el cambio en la normatividad para menores, antes código del menor 2737 de 1989, ahora ley 1098 de 2006; así como el reto de ser una Institución líder en el Cauca, hasta ahora la única que ofrece atención y formación integral para niños, niñas, adolescentes y jóvenes en el Departamento del Cauca.

\section{Aproximación diacrónica}

Para empezar, la adolescencia siempre ha sido concebida como un periodo crítico en el ciclo vital del ser humano. Encontrando soporte en los diferentes cambios físicos y psicológicos, podemos entender la adolescencia como ese período en el que un ser "adolesce" de aquello que deja atrás; es decir, la infancia, debiendo enfrentar las nuevas exigencias del entorno. Entendiendo así que, un/a adolescente sin ser niño/a y sin ser adulto/a, sí debe empezar a sortear diferentes retos que impone la sociedad, haciéndolo altamente vulnerable a riesgos como la drogodependencia, la paternidad/maternidad irresponsable y por qué no los actos delictivos o conductas punibles. Sumado todo esto a otras problemáticas de carácter familiar y socioeconómicas se van definiendo y perfilando las personalidades y conductas que rechaza la sociedad y que tanto apremia la intervención del Estado.

Diferentes estudios han abordado la problemática social que se presenta en los adolescentes que cada vez son más utilizados para diferentes actos delictivos sus causas y consecuencias. Se encuentran investigaciones de gran relevancia en Países como Nueva York (2001),

\footnotetext{
4 Entrevista realizada a (Fray Domingo Vergara, 2012). Administrador inicial del IFTM y administrador actual desde hace 6 años nuevamente.
} 
Chile (2007); y estudios comparativos entre Argentina, Bolivia, Brasil, Colombia, Chile, Ecuador, Paraguay, Perú y Uruaguay (2006), las cuales se orientan hacia la relación entre consumo de Sustancias psicoactivas y delincuencia en aras de fortalecer las Políticas Públicas que con el tema en mención se relacionan. En Colombia se han realizado otros estudios de igual relevancia, algunos en pequeña escala, es decir a nivel regional o departamental como por ejemplo el realizado en Barranquilla (2003) y otros a nivel Nacional, como el realizado por el Gobierno Nacional de la República de Colombia a través del Instituto Colombiano de Bienestar Familiar y la Dirección Nacional de Estupefacientes (2008-2009); éste último, a través de un análisis mixto entre lo cuantitativo y cualitativo permitió reconocer la estrecha relación entre consumo de sustancias psicoactivas y adolescentes con problemas de conductas delictivas con mayor incidencia en esta población que en el resto de la población adolescente y escolarizados.

En términos jurídicos esta problemática de conductas delictivas o actos punibles, en el contexto Colombiano se enmarca en el Sistema de Responsabilidad Penal para Adolescentes que establece el Código de la Infancia y la Adolescencia -Ley 1098 de 2006. Dicho sistema se fundamenta en un modelo restaurativo de justicia y de atención para los adolescentes infractores, con un concepto de persona en desarrollo con derechos y responsabilidades progresivas, en un proyecto de construcción de ciudadanía, democracia y vínculos sociales.

Durante muchos años la ley para los menores estaba dada desde el Código del Menor que actuaba considerando al menor inimputable; es decir, no responsable de toda conducta delictiva, y su fin era más protector que punitivo, lo cual llevó a que se generaran fenómenos como aumento en homicidios, sicariatos, porte de armas y tráfico y porte de estupefaciente entre otros; frente a lo cual el gobierno a través del congreso desarrolló un proyecto basado en la Ley Penal para adultos y ajustados a los menores de 18 años donde las actuaciones de los niños y adolescentes se reglamentaron bajo la ley de infancia y la adolescencia (Ley 1098 de 2006).

Antiguamente, la ley permitía la reivindicación de sus hechos a través de la privación de la libertad de manera excepcional, es decir, no todos eran privados de ésta y su caso era particular para cada delito, buscando en las decisiones legales que el adolescente se educara, se formara y cambiara su manera de pensar y actuar. Hoy día, al ser sancionados deben someterse al internamiento en instituciones que permitan lograr objetivos como son: educar, proteger, restablecer derechos, capacitarse y formarse para la vida sana, eliminando 0 minimizando el riesgo de perpetuar las conductas delictivas. Para todo este proceso, el Estado a través de su sistema de responsabilidad penal y civil tiene a su servicio diferentes instituciones que deben promulgar y 
ejecutar lo escrito en la Ley; existiendo en Colombia diferentes instituciones especializadas para cumplir con dicha misión, difiriendo sin embargo, en la metodología o pedagogía que emplean para conseguir los objetivos en pro de la misión.

\section{Caminando hacia la restitución de derechos}

Se retoma el objetivo central del presente escrito, que en todo caso, es describir la restitución de derechos, en la población adolescente sancionada por el Sistema de Responsabilidad Penal para Adolescentes. Por lo que me acuño, en la mirada que hace (Runciman, 1983) citado por Guber, frente al elemento distintivo de las ciencias sociales "la descripción", aludiendo que:

En todas las ciencias comparten dos niveles de comprensión: el primario o "reporte" informa qué ha ocurrido (el "qué"); el secundario o "explicación" alude a sus causas (el "por qué"); pero las ciencias sociales no puede prescindir de un nivel terciario de comprensión que es la "descripción", el cual se ocupa de lo que ocurrió según sus agentes (el "cómo es" para ellos). Un investigador social no puede entender una acción sin comprender los términos en que la caracterizan sus protagonistas. (Guber, 2001; p 32).

Por lo que constituye, un escrito a nivel terciario, sobre cómo es para ellos el Sistema de Responsabilidad penal para adolescentes SRPA; el cual, bajo la luz, del Código de la Infancia y la Adolescencia. Tiene por finalidad "garantizar a los niños, a las niñas y a los adolescentes su pleno y armonioso desarrollo para que crezcan en el seno de la familia y de la comunidad, en un ambiente de felicidad, amor y comprensión" (ley 1098, 2006, p. 15).

Así mismo, dicho sistema, se desarrolla bajo el apalancamiento de los tratados y convenios internacionales de derechos humanos ratificados por Colombia, bajo los cuales se interpretan los derechos y deberes consagrados en la Constitución Política de Colombia y los cuales conforman un sistema normativo superior "las normas contenidas en la Constitución Políticas y en los Tratados o Convenios Internacionales de Derechos Humanos ratificados por Colombia, en especial la Convención sobre los Derechos Del Niño" (art.6, Ley 1098, 2006: 16).

Por ello el proceso de restablecimiento de los derechos de adolescentes sancionados por el SRPA obedece a un marco normativo que a su vez orienta las herramientas de abordaje a los operadores de dicho sistema como lo es en Colombia por excelencia el Instituto Colombiano de Bienestar Familiar, a través de operadores, como es el caso de La Congregación de Terciarios Capuchinos con su extensión Instituto de Formación Toribio Maya de la Ciudad de Popayán. 
Para efectos del estudio etnográfico desarrollado, se abordaron aspectos relacionados con el reestablecimiento de los siguientes derechos: derecho a la vida y a la calidad de vida y a un ambiente sano, derecho la integridad personal, derecho a la rehabilitación y la resocialización, derechos de protección. Se enfatiza sólo en estos cuatro derechos, en consideración a que en ellos se encuentran de manera implícita los demás; se precisa además, que la ley establece la generalidad, más aquí, se detalla la manera y las prácticas que el Instituto de Formación Toribio Maya y sus colaboradores desarrollan avanzando hacia la restitución de derechos frente a los adolescentes que se encuentran en el proceso de internamiento preventivo.

\section{Orientaciones generales}

Para facilitar la comprensión de este tema se partirá de unas preguntas generadoras a manera de desarrollo conceptual.

\section{¿Qué es El SRPA?}

"El sistema de responsabilidad penal para adolescentes es el conjunto de principios, normas, procedimientos, autoridades judiciales especializadas y entes administrativos que rigen o intervienen en la investigación y juzgamiento de delitos cometidos por personas que tengan entre 14 años y 18 años al momento de cometer el hecho punible" (artículo 139, Ley 1098, 2006: 75).

Este sistema de justicia o sistema especializado que permite la garantía de la protección de los derechos niños niñas y adolescentes del territorio Colombiano, el cual surgió a través de un comité integrado por la Fiscalía General de la Nación, la Procuraduría General de la Nación y la Defensoría del Pueblo; quiénes sugirieron al Congreso de la República, una ley que presentara las especificaciones de responsabilidad frente a un hecho punible con un tratamiento diferencial del de los adultos, en tanto a la sanción se sobrepusieran los derechos del menor, promoviendo aspectos de resocialización rehabilitación y evitando que el adolescente perpetúe este tipo de conductas cuando se convierta en adulto; siendo la adolescencia un estadio del ciclo vital apta para que se den las adaptaciones correspondientes a resignificar su desarrollo biopsicosocial.

La (ley 1098, 2006) concibe al SRPA como un sistema más que punitivo, preventivo, excluyendo a los menores de 14 años, los cuales no entran a ser responsables del mismo; siendo aplicable sólo para quienes hayan cumplido los 14 años y en adelante hasta los 18 años de edad, a quienes se consideran responsables de la comisión de un delito y a quienes además se consideran inimputables para el derecho penal; es decir que son responsables del hecho cometido pero no pueden ser sancionados bajo el sistema responsabilidad penal para adultos en 
tanto el sistema especial para su edad hace prevalencia de los derechos de niños niñas y adolescentes orientado al tema de "rehabilitación readaptación y reeducación" (Corte Constitucional, Sentencia C -817, 1999).

Esto de por sí, juzga un sistema diferente donde si bien está se reconoce la conducta cometida por el adolescente no se desconoce la responsabilidad que el mismo pese a su inmadurez del desarrollo biopsicosocial pueda tener. Para ello es asignado un defensor de familia quien apoya el cumplimiento de cada uno de los derechos que desde el momento de la aprehensión hasta el día que termine la sanción el adolescente tiene derecho.

\section{¿Cómo aplica el SRPA?}

El SRPA aplica a través de las sanciones que se les impone a los adolescentes cuando se les encuentra responsables de un acto que merece ser castigado, éstas son: la amonestación, la imposición de reglas de conducta, la prestación de servicios a la comunidad, la libertad asistida, la internación en medio semicerrado, la privación de libertad en centro atención especializada.

La privación de la libertad en centro atención especializada CAE, se aplica a personas o adolescentes mayores de 14 años y menores de 18 años que se han hallado responsables de homicidio doloso, secuestro o extorsión, en todas sus modalidades; para dichos adolescentes, la privación de la libertad en centro de atención especializada tiene una duración de 2 hasta 8 años. Asimismo los mayores de 16 años y menores de 18 años que se hayan encontrado responsables de la comisión de delitos cuya pena mínima establecida es entre 1 y 5 años. Dado el establecimiento de sanciones el adolescente puede cumplir su mayoría de edad privado de su libertad y faltarle algunos años más para terminar su sanción por lo que "los centros de atención especializada tendrán una atención diferencial entre los adolescentes menores de 18 años y aquellos que alcanzaron su mayoría de edad y deben continuar con el cumplimiento de la sanción Esta atención deberá incluir su separación física al interior del centro " (Parágrafo del artículo 187 de la Ley 1098 2006: 96). Pese a ello, los demás derechos siguen prevaleciendo hasta el momento de terminar su sanción

\section{¿Cuáles son los derechos de los adolescentes privados de la libertad?}

Los derechos que prevalecen en la medida de privación de la libertad son los que se consagran en la constitución política, los derechos de los niños y los que se enuncian a continuación: 
$>\quad$ Permanecer internado en la misma localidad, municipio o distrito o la más próxima al domicilio de sus padres, representantes o responsables.

$>\quad$ Que el lugar de internamiento satisfaga las exigencias de higiene, seguridad y salubridad, cuenta con acceso a los servicios públicos esenciales y sea adecuado para lograr su formación integral.

$>\quad$ Ser examinado por un médico inmediatamente después de su ingreso al programa de atención especializada, con el objeto de comprobar anteriores vulneraciones así tendría personal y verificar el estado físico mental que requiera tratamiento.

$>\quad$ Continuar su proceso educativo de acuerdo con su edad y grado académico.

$>\quad$ Que se le mantengan cualquier caso separado de los adultos.

$>\quad$ Derecho participar en la elaboración del plan individual para la ejecución de la sanción.

> Derecho a recibir información sobre régimen interno de la institución, especialmente sobre las sanciones disciplinarias que para andar serle aplicables y sobre los procedimientos para imponerlas y ejecutarlas.

> No ser trasladado arbitrariamente del programa de cumple la sanción. el traslado sólo podrá realizarse por una orden escrita la autoría judicial.

> No ser sometido a ningún tipo de aislamiento.

$>\quad$ Mantener corresponden se comunicación con sus familiares y amigos y recibir visitas por lo -1 vez a la semana.

$>\quad$ Tener acceso a la información de los medios de comunicación.

(Art. 188 Ley 1098 2006: 96)

\section{¿Qué se entiende por restitución de derechos?}

"Se entiende por reestablecimiento de los derechos de los niños, las niñas y los adolescentes. La restauración de su dignidad e integridad como sujetos y de la capacidad para hacer un ejercicio efectivo de los derechos que les han sido vulnerados" (artículo 50, Ley 1098, 2006: 43). Lo cual sugiere obligatoriedad del Estado y sus Entes para su estricto cumplimiento, así este SRP para adolescentes difiere del SRP para adultos, en tanto no constituye una sanción represiva si no que constituye una medida correctiva, protectora, educativa y restaurativa.

\section{Tiempo y espacio, restitución de derechos vs castigo. Descripción y relatos.}

Las vivencias viajan a través del tiempo o el tiempo viaja a través de las experiencias que acontecen en la cotidianidad, en el corazón inexorable de los adolescentes. Un día tras otro suman éstos, el tiempo de sanción impuesta por el juez, bajo la medida de privación de la 
libertad en centro de atención especializada; la cuál más que un espacio físico para la comunidad que administra u operan el SRPA, es un ambiente formativo según lo define la Propuesta Amigoniana:

La Propuesta Pedagógica Amigoniana establece un método integral de atención, que se desarrolla paulatinamente sustentado por un sistema de auto corrección y de acompañamiento, propio del sistema Pedagógico Amigoniano. (Plan Amigoniano para la atención e intervención de adolescentes en vulnerabilidad y conflicto con la ley, 2010, p. 3).

Antes de describir el pensar de los adolescentes en torno a las categorías Castigo vs espacio y tiempo, es conveniente precisar algunos aspectos como que el SRPA, no contempla la privación de la libertad como un castigo si no como una sanción que deberá vivir en un Centro de Atención Especializada a modo de que se garanticen los derechos del menor por el tiempo que establezca el juez de garantías debe durar dicha sanción

La cual además alude que en materia de responsabilidad penal para el adolescente, tanto el proceso como las medidas que se tomen tendrán un carácter pedagógico, específico y diferenciado del sistema de adultos, respetando así su protección integral y buscando una justicia restaurativa, la verdad y la reparación del daño.

De tal manera, el concepto que maneja la Procuraduría (2006) como privación de la libertad es entendida como una forma de internamiento, en un establecimiento público o privado, ordenada por la autoridad judicial, del que no se permite al adolescente salir por su propia voluntad, sólo lo puede hacer para efectos de estudio con autorización escrita del juez y aprobación de su defensor; dicha privación sólo se procede para los menores de edad que en el momento de cometer el deliro hayan cumplido 14 años y sean menores de 18. Procediendo ésta, como medida pedagógica, deben los adolescentes durante su estadía estar separados de los adultos en establecimientos de atención especializada en programas del Sistema Nacional de Bienestar Familiar (I.C.B.F). Es por ello que Bienestar Familiar contrata los operadores del mencionado programa de atención especializada, que cuenten con la experiencia y propuestas de intervención específicas acordes a las exigencias de la ley de infancia y adolescencia.

En Colombia el I.C.B.F cuenta con diferentes operadores, sin embargo la mayor cobertura de atención a la población adolescente en conflicto con la ley está a cargo de la Congregación de Religiosos Terciarios Capuchinos, creadora de la propuesta Pedagógica Amigoniana, cuyo nombre se deriva de su fundador Fray Luis Amigó, acogiéndose a sus 
postulados y por supuesto a los lineamientos que establece el I.CB.F y el SRPA.

Estas disposiciones son conocidas por los adolescentes generando expresión de sentimientos donde afloran palabras como sanción o "castigo" para ellos, una representación que se materializa en el internamiento en un espacio físico, donde todos están por delitos similares aún cometidos en diferentes circunstancias. En ese sentido, cualquier situación definida por los adolescentes, tendrá el particular pensamiento situado en una afirmación colectiva acerca de la "imagen del mundo" durante su sanción o "castigo" podrán al fin aprender lo que es válido para la totalidad de la sociedad en condiciones normativas.

Más allá, de la claridad, que pueden tener frente a que ya son personas mayores de 14 años, que han sido hallados responsables de la comisión de delitos cuya pena mínima establecida en el código penal es o excede "seis" años de internamiento, su indignación, no les permite persuadir a sus defensores de que el SRPA contempla igualmente, que parte de la sanción impuesta podrá ser sustituida por el establecimiento de presentaciones periódicas, servicios a la comunidad, el compromiso de no volver a delinquir y guardar buen comportamiento, por el tiempo que fije el juez. Prefieren no hacerlo, para no correr el riesgo de reincidir al encontrarse en su contexto real, con sus amigos de barrio, con las necesidades de su familia, con la desesperanza aprendida de no saber más que hacer, que delinquir. De ahí que, en el discurso de los adolescentes emerge de manera permanente, anécdotas de lo que fue su vida antes de ingresar a la institución, a manera de justificar sus actos punibles y comentarios sobre el tiempo que les resta privados de estar libres. Los adolescentes juzgan de infortunados por haber sido hallados en la comisión del delito, como injusto porque mientras el SRPA piensa en un estadio compuesto de actividades controladas por el tiempo y el espacio para restituir sus derechos, ellos sienten haber perdido el principal derecho "el de la libertad", vista en perspectiva de la siguiente manera: 
Figura 1. Economía del Castigo en perspectiva.

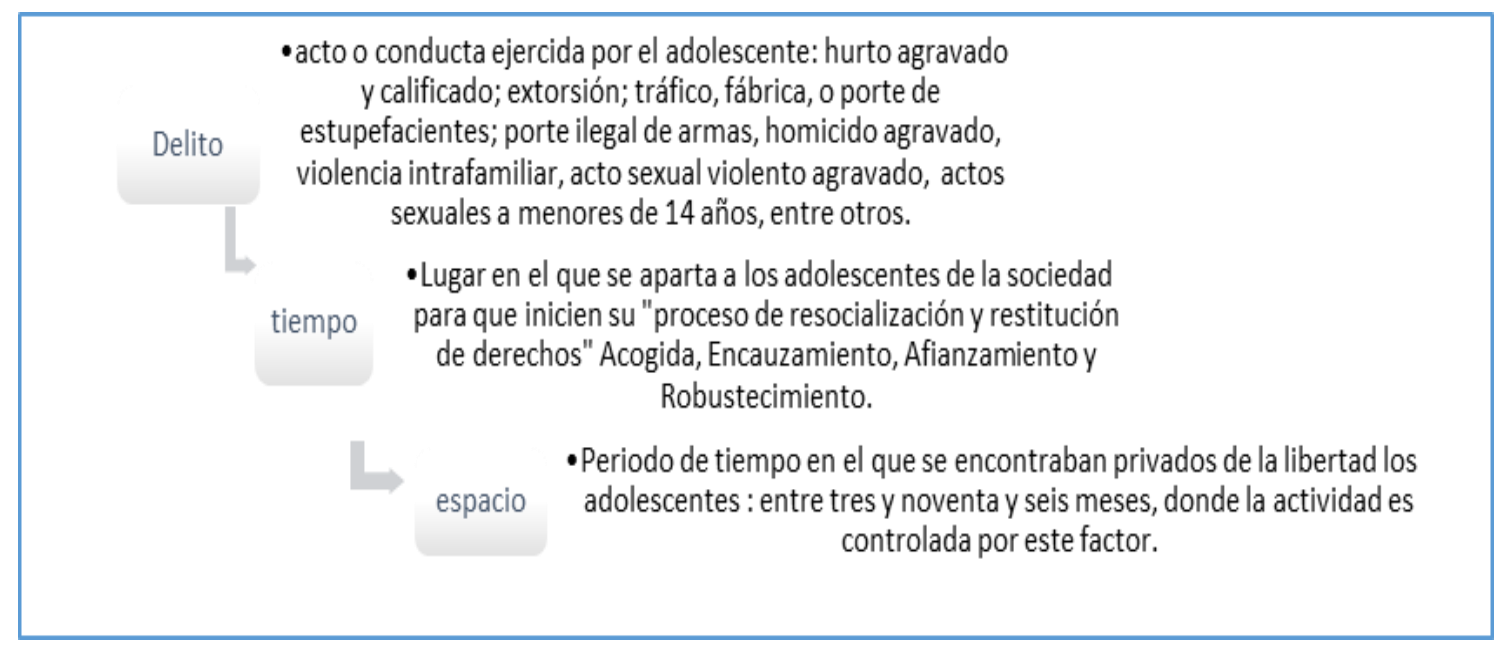

Fuente: (Elaboración propia, 2013), a partir del planteamiento de (Foucault, 2005, p. 73).

Por añadidura, la pérdida de libertad, en contraste con su realidad, se corrobora, a partir de la exploración de los archivos documentales durante el trabajo de campo sobre las sanciones que cada uno de los adolescentes deben cumplir. Por lo que logré construir los marcos de referencia de los actores a partir de su verbalización, en relación a la materialización de su sanción. En la siguiente tabla se consignan, algunos casos contenidos en los archivos documentales. Con relación a las sanciones que presentaban los 108 adolescentes privados de su libertad a diciembre de 2012, se escogieron 30 al azar a modo de resumir dicha información.

Lo que hace suponer, una construcción acerca de castigo vs espacio, en un sentido estricto, desde el punto de vista del SRPA, el cual no relaciona la sanción como castigo, al considerar que durante este tiempo de privación de la libertad el adolescente tendrá una garantía de derechos. Sin embargo, el concepto estricto de sanción sugiere un castigo que se impone al que no cumple la norma o tiene un comportamiento incorrecto. Lo cual, para un adolescente constituye, el primer elemento clave de que está sometido a un castigo, el no poder hacer uso de su tiempo en los espacios que él desea, si no en un medio impuesto y privado del compartir con sus amigos de barrio y sus familiares, relacionado así, con el siguiente postulado:

¿Debería ser castigado un crimen tal? ¿¿De acuerdo con qué medida? ¿ De qué utilidad podría ser su castigo en la economía del poder de castigar? Sería útil en la medida en que pudiera reparar el "mal hecho a la sociedad". Ahora bien, si dejamos de lado el perjuicio propiamente material- que incluso irreparable como en un asesinato, es de poca 
monta al nivel de una sociedad entera_ el daño que hace un crimen al cuerpo social es el desorden que introduce en él: el escándalo que suscita, el ejemplo que da, la incitación a repetirlo si no ha sido castigado, la posibilidad de generalización que lleva en sí. Para ser útil, el castigo debe tener como objetivo las consecuencias del delito, entendidas como la serie de desórdenes que es capaz de iniciar. " la proporción entre la pena y la calidad del delito está determinada por la influencia que tiene sobre el orden social el pacto que se viola" (Foucault, 2005, p. 56).

Pese a ello la realidad es que, frente a un mismo delito cometido, se dan diferentes tipos de sanción y acaecen diferentes características de las mismas; a partir de lo cual podríamos preguntarnos żqué justicia restaurativa podría ofrecérsele al adolescente y a las víctimas en una sanción que dura 4 meses?, el adolescente, podrá seguir estudiando en la misma institución posterior al cumplimiento de su sanción, pero ¿̇será que sus otras necesidades axiológicas, estarán cubiertas, para continuar con el proyecto de vida que allí empezó a trazar?

Paradójicamente, algunos adolescentes, que tienen sanciones de 6 y 7 años, se encuentran agradecidos con la vida, con ICBF, con el Instituto, porque gracias a su llegada allí pudieron culminar sus estudios de secundaria, actualmente se encuentran matriculados a algún pregrado. Pero, $\dot{\imath}^{\dagger}$ ener que ser el asesino de alguien para que el Estado atienda su vulnerabilidad? Bajo esta perspectiva, sus discursos, toman relevancia cuando el medio ambiente o contexto en el cual se encuentran los llevaba a pensar y sentir determinados por el mismo.

Es interesante señalar $\dot{z}$ Cómo consideran los adolescentes que viven su proceso de internamiento, subsanando la idea de que están castigados por haber violado la norma? Soportados en la idea que su "castigo es temporal" hacen cuentas del tiempo que llevan y día a día restan del tiempo que ha sido impuesto por el juez. Además, algunos convencidos de que el proceso es lo mejor para ellos, otros no tanto, pero por lo menos sí pueden hacerle creer a los demás de que poco a poco se convencen de ello.

Como pudiera haberlo descrito Foucault hace algunos años si existe una sanción o castigo que lleva a la privación de la libertad en una "prisión" o "cárcel" existirá quien realice el control de la actividad "carcelero", que bajo este sistema toma forma de educador. Es así, como una jornada empieza muy temprano, cinco y treinta de la mañana el timbre o la campaña suena y todos deben levantarse y dar inicio a la organización de su cama y del dormitorio, posteriormente pasan a bañarse por turnos, pasan al comedor para desayunar, donde llevan a cabo el ritual de la bendición de los alimentos, posteriormente se hace el encuentro de la mañana empezando por relatar su estado de ánimo, todas estas y demás actividades, controladas por el educador. 
Cada adolescente debe comentar en voz alta su estado de ánimo, si éste es bajo, solicita al grupo le oriente qué hacer, especialmente, al educador, psicólogo, trabajadora social y/o a un adolescente que haya avanzado en el proceso. Así un ritual, que para la Congregación creadora del Plan Amigoniano representa un fin terapéutico en su restauración de derechos, para los adolescentes, implica una rutina que acompaña su privación de la libertad. Una situación, donde se les reprime en su libertad de pensamiento, frente a las conductas y vivencias pasadas; de ahí que, el imaginario de los adolescentes frente a este ritual, es que les quieren cambiar en su forma de ser, cuando deben repetir de manera permanente la Filosofía Amigoniana.

A 1. ¿ No ve lo difícil que es ser en un medio donde el reconocer que dejamos de ser, hace parte de lo que recitamos a diario y más aún cuando yo he sido malo desde chiquito? Pille, pille bien lo que dice la filosofía amigoniana, pille nada más y analice. Es que lo que quieren acá es que uno cambie, pero eso es muy difícil. Repetimos siempre ¿Por qué estamos aquí? Y hay que responder:

Estamos aquí porque no existe refugio alguno donde escondernos de nosotros mismos, mientras la persona no se confronte en los ojos ni en el corazón de los demás, está escapando, mientras no comunique sus secretos, no hallará reposo. El hombre que teme ser conocido, no puede conocerse así mismo, ni conocer a los demás; está sólo. Fuera de nuestros puntos comunes, ¿Dóndemás podemos hallar tal espejo? Reunidos aquí, la persona puede a fin de cuentas manifestarse claramente a sí mismo, no como el gigante de sus sueños ni el enano de sus temores, si no como un hombre parte de un todo, con su contribución para ofrecer. Sobre este terreno podemos echar raíces y crecer, ya no solos como la muerte, si no vivos para nosotros mismos y los demás" (Filosofía, Amigoniana). ${ }^{5}$.

Imagínese usted, acá tenemos que dejar de ser todo lo que éramos incluso desde chiquitos, porque yo cogí calle muy pelado. Pero cuando salgamos qué, todo vuelve a estar ahí, el peligro, la adrenalina, el tener que trabajar para sobrevivir. Ahí tenemos que volver a pensar en nosotros mismos, porque claro, acá es muy fácil pensar en el otro. Tenemos buena dormida, comida estilo hotel 5 estrellas, tenemos estudio gratis, tenemos ropa, regalos de navidad, actividades diarias para divertirnos, como lo es el festival amigoniano, el festival de la canción, las olimpiadas, la semana Santa, La semana de la Virgen de los Dolores, tantas cosas que el Chinche' ${ }^{\text {hace }}$ para que nosotros estemos bien. Pero a veces, uno se pone a pensar en los que se evaden, o se vuelan de acá, pues sí uno encontrará la libertad de verdad valdría la pena, pero

5 Entrevista realizada a adolescente oriundo de Puerto tejada: edad 15 años. Le gustaba el seudónimo Ovejita Negra

6 Chinche: Apelativo que los adolescentes le dan al Padre Director, como muestra de su afecto hacia él. 
también tendrá más posibilidades de encontrar la muerte. Es como querer estar, y no querer estar. Sabemos que afuera no podemos estar mejor que acá, porque obvio ya no va a estar el Toribio 'para darnos todo. Pero igual, otro ladito de uno dice que sí es mejor estar afuera para poder hacer todo lo que acá no se puede, ¿̇me entiende?. (Adolescente, 2013).

Durante el resto del día, el tiempo es empleado en diferentes rutinas académicas, deportivas y pedagógicas básicamente. La academia es obligatoria, para todos los adolescentes, en la mañana después del encuentro inician su jornada académica de acuerdo al grado al que los hayan matriculado a su ingreso en la institución. El instituto de Formación Toribio Maya está certificado como institución educativa por lo que pertenece a la Secretaria de educación Municipal y su planta de personal docente se financia con recursos recursos de oferentes. La formación académica es cíclica y está regulada por los lineamientos del Ministerio de Educación Nacional. Los adolescentes que han culminado sus estudios primarios y secundarios, tienen la posibilidad de cursar estudios de pregrado en las universidades de la ciudad financiados por sus familias y en algunos casos por el I.C.B.F. Previa inscripción y matrícula para el pregrado deben buscar el permiso con el juez y disposición del acudiente que lo recoja en el Instituto de Formación Toribio Maya, lo lleve a la Universidad y viceversa. Lo que evidencia un orden distinto del modelo punitivo de siglos pasados empero sí quizá un mismo fin.

Pero el efecto más importante quizá del sistema carcelario y de su extensión mucho más allá de la prisión legal, es que logra volver natural y legítimo el poder de castigar, y rebajar al menos el umbral de tolerancia a la penalidad. Tiende a borrar lo que puede haber de exorbitante en el ejercicio del castigo. Y esto haciendo jugar uno con respecto del otro los dos registros en que se despliega: el -legal- de la justicia, y el -extralegal- de la disciplina. En efecto, la gran continuidad del sistema carcelario de una y otra parte de la ley y de sus sentencias procura una especie de garantía legal de mecanismos disciplinarios, a las decisiones y a las sanciones que emplean. (Foucault, 2005, p.184).

Esto explica sin duda lo que el SRPA supone como sanción, inversamente a lo que supone Foucault como castigo.

Es aquí dónde empieza un ciclo de restauración de derechos, agotado en lo jurídico, dónde sólo a partir de la privación de su libertad, los adolescentes, pueden acceder a derechos básicos como la educación, la salud, la vivienda digna, la alimentación, la protección. Lo que además, genera tranquilidad al aparato de la justicia, ya que la contraprestación a la restitución de derechos, es la inactividad delincuencial, por parte de los adolescentes durante su periodo de internamiento. 


\section{Tensiones}

Aun así, quedan vacíos en el proceso de restitución de derechos, ¿Quién garantiza la continuidad en la restitución de derechos, una vez el adolescente termina la sanción?

Merece la pena, trazar un paralelo entre la teoría ecológica donde la interacción de los ambientes Microsistema, Mesosistema y Exosistema (Bronfenbrenner, 1987, p. 44), son de suma importancia y la concepción, que tienen (McCold y Wachtel, 2003), frente a la justicia restaurativa. Donde se evidencia un proceso complejo e inexistente en el sistema que opera en Colombia; pudiendo ratificar, que la inmersión de los diferentes ambientes en un contexto de práctica real, pudiera quizá vislumbrar un aporte al proceso de restauración de derechos a víctimas y victimarios.

Con más motivo, y para finalizar se concluye que el SRPA, debería tener certezas en cuanto a que éste se desarrolle en un modelo pedagógico, que bajo ninguna circunstancia acuñe la privación de la libertad, como sistema de seguridad, ni no como sistema de oportunidad. Por el contrario, su fin debería permear los contextos de vulnerabilidad donde se desarrolla el adolescente, partiendo del sentido mismo del delito, sin apartarlo del medio en que se desenvuelve.

El delito es un fenómeno que acontece entre personas y que por ello debe ser tratado en su dimensión social y no como una trasgresión de las normas; busca la reparación de las víctimas, y a través de ella la recuperación para la sociedad del victimario, es decir, no renuncia a su tarea educativa para con los jóvenes; entiende que los delincuentes pertenecen a una familia y comunidad y por lo tanto es con la participación activa de éstas que se puede plantear el proceso restaurativo, estableciendo niveles de responsabilidades; respeta el sistema judicial que le da marco y mantiene una estrecha relación con él; el énfasis en el tratamiento del delito no está en la seguridad, sino en la construcción de valores y de una ética de la responsabilidad. Pues reconoce que el victimario ha dañado a la víctima, a la sociedad y a sí mismo; busca equilibrar la relación de poder entre víctimas y victimarios; a diferencia del modelo punitivo, la justicia restaurativa no se declara neutral, por el contrario, tiene una orientación moralizante (Britto, 2010, p. 49).

De modo que la visión e intervención actual del SRPA, como la resolución del problema a través de la oportunidad de adaptarse a un plan para reparar el daño o impedir que se repita, privando al adolescente de su libertad, resulta insuficientes. Porque no se está incidiendo sobre los contextos, donde se desenvuelve el adolescente; de modo que, algunas necesidades son cubiertas mientras el adolescente se encuentra bajo la medida de internamiento preventivo, pero posterior a su sanción, y su inmersión al contexto natural, las 
condiciones o factores del mismo, pesan más que la intención de resocialiación o reeducación.

Para finalizar, a juzgar por lo que se relata como una pequeña escena en el presente escrito, resultado de una magnífica vivencia de investigación etnográfica, seguramente moviliza a pensar en que se necesitan menos centros de reeducación, menos defensores de familias y menos jueces, empero sí, más programas de prevención y una política pública con profesionales de pantalones bien puestos sin temor a desarrollarla y sin la mediocridad aunada a la sed de mostrar meramente resultados estadísticos.

\section{Bibliografía}

Arce, R., Fariña, F., \& Vázquez, M. (2011). Grado de competencia social y comportamientos antisociales, delictivos y no delictivos en adolescentes. (Spanish). Revista Latinoamericana De Psicología, 43(3), 473-486.

Bronfebrenner, Urie. 1987. La ecología del DESARROLLO A ESCALA HUMANA. Bogotá: Ediciones Paidós Iberica, S.A.

Columbu, L., Catena, A., \& Illescas, S. (2012). La percepción de los adolescentes sobre las motivacionese influencias que llevan a un joven a cometer un delito. (Spanish). Boletín Criminológico, (137), 1-6.

Da Costa, M. M., \& Hermany, R. (2008). EL PODER LOCAL CÓMO LOCUS PRIVILEGIADO PARA LA IMPLEMENTACIÓN DE LAS POLÍTICAS PÚBLICAS DE PREVENCIÓN DE LA DELINCUENCIA JUVENIL. (Spanish). Revista De Derecho (15105172), 7(14), 17-28.

De Tezanos. Araceli. 2002. Una etnografía de etnografía. Bogotá: Ediciones Antropos Ltda.

Foucault, Michel. 2005. Vigilar y castigar: nacimiento de la prisión. Argentina: Siglo XXI, Editores Argentia, S.A.

García, M., Martín, E., Torbay, Á., \& Rodríguez, C. (2010). La valoración social de la Ley de Responsabilidad Penal de los Menores. (Spanish). Psicothema, 22(4), 865-871. 
Goetz, J.P y M.D.Lecompte.1984. Etnografía y diseño cualitativo en educación. Madrid: Ediciones Morata, S.A.

Guber, Rosana. 2004. El salvaje metropolitano. Reconstrucción del conocimiento social en el trabajo de campo. Argentina. Editorial Paidós

Guber, Rosaana. 2001. La etnografía. Método, campo y reflexividad.Colombia. Editorial Cargraphis S.A-Impresión Digital.

Hernández, Luis; María Antonieta Goytia Jiménez y Arturo Ramos Pérez. 2004. Enfoques metodológicos críticos e investigación en ciencias sociales. México: Plaza y Valdés, S.A.

Jiménez, Á. 2003. Retacitos de vida. Barranquilla: Don Bosco.

Leblanc, L., \& Robert, M. (2012). La innovación psicosocial: planificar su implementación y difusión para prevenir la delincuencia juvenil. (Spanish). Universitas Psychologica, 11 (4), 1125-1134.

León, Oswald; Juan Calderon y Sandra Romero. 2010. Aproximación a los Referentes Teóricos y Conceptuales que Fundamentan la Propuesta pedagógica Amigoniana. Bogotá. Congregación de Religiosos Terciarios Capuchinos Provincia San José.

Malinowski, Bronislaw. 1986. Los Argonautas del Pacífico occidental. España. Editorial Promotora de Ediciones, S.A.

Oficina de las Naciones Unidas contra la Droga y el Delito (UNODC) y Comisión Interamericana para el Control del Abuso de Drogas (CICAD/OEA) 2006. "Jóvenes y drogas en países sudamericanos: un desafío para las políticas públicas". Primer estudio comparativo sobre uso de drogas en población escolar secundaria de Argentina, Bolivia, Brasil, Colombia, Chile, Ecuador, Paraguay, Perú y Uruguay.

Pérez, Augusto et al.2008. "Fracciones atribuibles en las relaciones entre crimen y drogas en Colombia". Informe final del proyecto financiado por el Ministerio del Interior y de Justicia de Colombia, la Dirección Nacional de Estupefacientes y la CICAD/OEA; y la cooperación del Inpec. Bogotá.

Perinat, Adolfo et al.2003. Los adolescentes en el sigo XXI. Barcelona: Editorial UOC.

Procuraduría General de La nación. 2006. "Ley 1098 Código de la infancia y la adolescencia". Bogotá.

Pontificia Universidad Católica de Chile: Facultad de Ciencias Sociales - Instituto de Sociología, y Servicio Nacional de Menores (SENAME). 2007. "Estudio de prevalencia y factores asociados en adolescentes infractores de ley". Santiago de Chile.

República de Colombia: Dirección Nacional de Estupefacientes y Ministerio de la Protección Social. 2009. "Estudio Nacional de Consumo 
de Sustancias Psicoactivas en Colombia". Bogotá: Editora Guadalupe. Ver también: http://odc.dne.gov.co.

Sabato, E. (2000). La resistencia. Argentina. Editorial Planeta Argentina. (p28)

Sen, Amartya. 2000. Desarrollo y Libertad. México. Editorial Planeta.

Taylor, S.J y R, Bogdan.1987. Introducción a los métodos cualitativos de la investigación cualitativa. España: Ediciones Paidós América, S.A.

Toro, Ricardo José y Luis Eduardo Yepes. 2005. Fundamentos de Medicina. Psiquiatría. Medellín. ClB.

Trouillot, Michel-Rolph. 2011. Transformaciones globales. La antropología y el mundo moderno. Popayán: Universidad del Cauca y Universidad de los Andes.

Zuazua, Alberto. 2007. El proyecto de autorrealización. Cambio, curación y desarrollo. Alicante. Editorial Imprenta Gamma.

Zapata, Oscar. 2005. La aventura del pensamiento crítico.Herramientas para elaborar Tesis e investigaciones socioeducativas. México. Editorial Paax México. 